\title{
Serum carcinoembryonic antigen in clinical disorders
}

\author{
S. N. BOOTH, J. P. G. KING, J. C. LEONARD, AND P. W. DYKES \\ From the Department of Experimental Pathology, The Medical School, University of Birmingham, and The \\ General Hospital, Birmingham
}

SUMMARY Carcinoembryonic antigen (CEA) levels have been measured in the serum of 490 patients and 93 normal controls using the double antibody radioimmunoassay technique. Levels were elevated in 71 of patients with carcinomata of the gastrointestinal tract and in $42 \%$ with other types of malignancy. In patients with non-neoplastic disease of the gastrointestinal tract and liver, elevated levels were found in 14 and $66 \%$ respectively. In general the CEA level tends to be higher in cancer patients with haematogenous dissemination. Following complete surgical removal of a tumour, levels fall to normal within 14 days in the majority of patients. Of 33 patients studied during follow up, elevated levels were found in 12,10 of whom had evidence of recurrence.

The significance of these findings and the possible application of CEA assay in clinical practice are discussed.

In recent years many attempts have been made to detect macro-molecular substances specific for human tumours, which if liberated into the body fluids could form the basis of an assay useful in the early diagnosis and management of malignant disease. One of the best such examples is the assay of chorionic gonadotrophin in patients with choriocarcinomata (Bagshawe, 1969).

Well documented evidence has existed for some time of specific antigens in experimentally induced tumours of animals (Old, Boyse, Clarke, and Carswell, 1962). The same is not true for human tumours. Although there have been many reports of apparently human tumour-specific antigens, in the majority of instances this specificity is now open to doubt. In 1965 Gold and Freedman described an antigen which was identical in 12 different colonic carcinoma specimens examined (Gold and Freedman, 1965a). They later detected the same antigen in extracts of other gastrointestinal carcinomata together with extracts of foetal intestine, liver, and pancreas during the first two trimesters of pregnancy (Gold and Freedman, 1965b). Further, they were unable to demonstrate this antigen either in normal tissues or in non-entodermally derived malignant tumours, and therefore called it carcinoembryonic antigen (CEA). The existence of this antigen in other than carcinomatous or foetal tissue has since been extensively studied and found in normal human Received for publication 9 July 1973. colon (Martin and Martin, 1970) and pooled normal serum (Chu, Reynoso, and Hansen, 1972). This change in view of the specificity of CEA is reflected in the reports of radioimmunoassay results in a wide range of clinical groups. An initial claim of $97 \%$ positivity in patients with carcinoma of the colon (Thomson, Krupey, Freedman, and Gold, 1969) has not been reproduced (Lo Gerfo, Krupey, and Hansen, 1971; Moore, Kupchik, Marcon, and Zamcheck, 1971; Joint Canadian and American, Study, 1972; Laurence, Stevens, Bettelheim, Darcy, Leese, Turberville, Alexander, Johns, and Neville, 1972) and substantial overlap is now agreed between malignant and non-malignant groups. Clinical conditions on which attention has been focused include those posing diagnostic difficulty with carcinoma, hence the importance of overlap between results in inflammatory bowel disease and carcinoma of the colon and also between peptic ulcer and gastric cancer.

Radioimmunoassay has been carried out in three major ways. The first, the Farr assay, used by Gold and his collaborators (Thomson et al, 1969), utilizes precipitation of the antigen-antibody complex by ammonium sulphate. Hansen replaced ammonium sulphate with zirconyl phosphate gel (Z-gel) (Lo Gerfo et al, 1971) and this forms the basis of the test developed for commercial purposes by Hoffman La Roche Inc. Finally, a double antibody test was developed by Todd using horse antigoat IgG to 
precipitate the CEA-anti-CEA complex (Egan, Lautenschleger, Coligan, and Todd, 1972). This is the only method which does not involve preliminary perchloric acid extraction of the specimens.

In this study, the second using the double-antibody technique, we have been able to include sizeable groups of patients suffering from ulcerative colitis, Crohn's disease, and cirrhosis.

\section{Patients and Methods}

The majority of subjects included in this study were either patients in the wards or attending outpatient clinics at Birmingham General Hospital. The normal controls, whose ages range from 19 to 63 years, were either members of staff of the Department of Experimental Pathology, University of Birmingham, or were participating in a normal population biochemical profile screening programme.

In all patients a definite diagnosis had been made by standard clinical, radiological, and laboratory methods, and where appropi iate, eg, for all malignant tumours, by histological examination. All gastric, colo-rectal, and breast neoplasms were graded with respect to the clinical, operative and pathological findings, the TNM grading being used for breast and gastric lesions (Kennedy, 1970) and Dukes' classification for colonic tumours (Dukes, 1940). In patients with inflammatory bowel disease the diagnosis was established by radiological or operative findings supported in almost all cases by histological examination. The severity of the disease process was graded with respect to clinical and biochemical indices and the extent of the disease by radiological or surgical findings.

Samples of blood $(10 \mathrm{ml})$ were drawn by venepuncture into a sterile container and the serum was separated within two hours. Each sample was coded and stored at $-20^{\circ}$ until use and assays were performed without knowledge of the diagnosis in every case.

The assay method used is the double antibody technique (Egan et al, 1972) as modified by Laurence et al (1972). Serum samples $(0.2 \mathrm{ml})$ were assayed in duplicate. The assay is capable of measuring CEA in amounts from 0.5 to $70 \mathrm{ng} / 0.2 \mathrm{ml}$ with an agreement in duplicate tubes that is normally within $10 \%$. Repeated observations on the same serum sample established a standard error for the assay of $\pm 0.6 \mathrm{ng} / \mathrm{ml}$ for a mean value of $13.2 \mathrm{ng} / \mathrm{ml}$. Purified CEA, specific CEA antiserum, and horse antigoat IgG, for use in the assay, were kindly supplied by Dr C. W. Todd, City of Hope National Medical Center, Duarte, California. The CEA has been shown to be immunologically indistinguishable from that of Gold and was prepared by perchloric acid extraction of hepatic metastases followed by sequential gel filtration on Sepharose 4B and Sephadex G200 (Coligan, Lautenschlegar, Egan, and Todd, 1972). The CEA antiserum was prepared in goats by injecting microgram quantities of the purified CEA subscapularly in complete Freund's adjuvant (Egan et al, 1972). The CEA for the assay was labelled with ${ }^{125}$ I weekly by the chloramine $\mathrm{T}$ method (Egan et al, 1972) and standard curves were produced for each preparation.

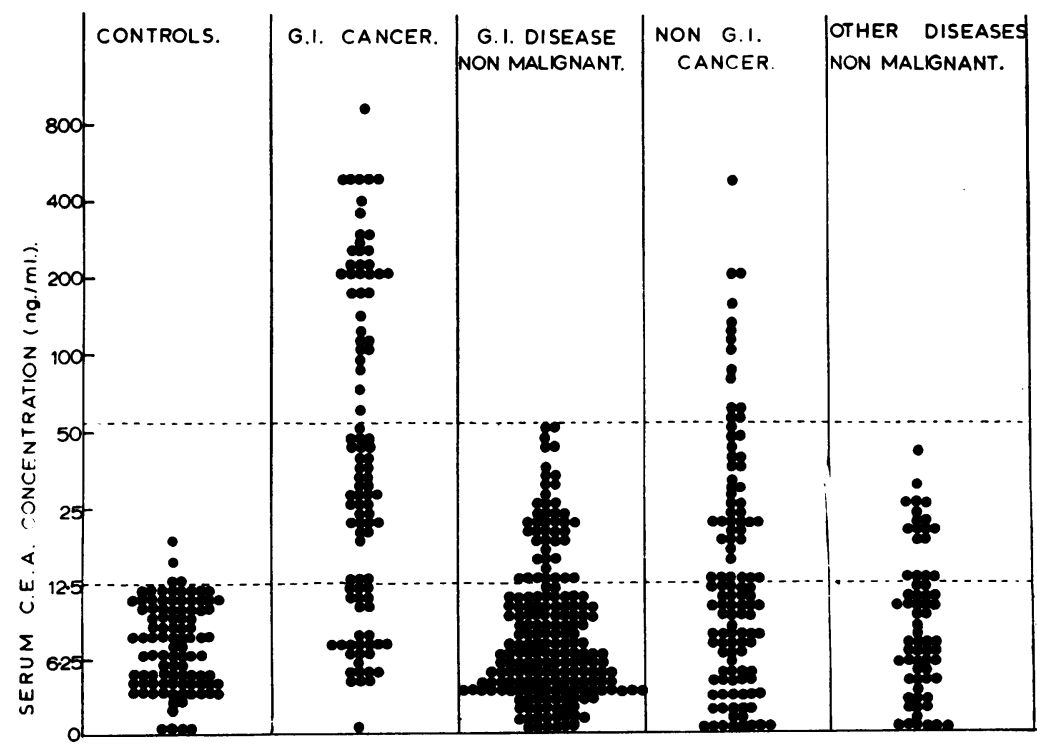

Fig 1 The overall distribution of serum CEA values in 583 patients and normal controls. 


\section{Results}

The overall distribution of serum CEA levels in 490 patients and 93 normal subjects plotted logarithmically is shown in figure 1 .

The sera of 93 normal controls have been examined and in 91 of these the level was $12.5 \mathrm{ng} / \mathrm{ml}$ or less. In two subjects with levels of 15 and $17 \mathrm{ng} / \mathrm{ml}$ there was no clinical evidence of malignant disease. The range of $0-12.5 \mathrm{ng} / \mathrm{ml}$ is consistent with results obtained by Laurence et al (1972) and has therefore been accepted as the upper limit of normality for the purpose of this study.

\section{GASTROINTESTINAL DISORDERS}

Results obtained from the sera of 273 patients suffering from a variety of gastrointestinal diseases are summarized in table I. In a total of 96 estimations from patients with gastrointestinal malignant disease elevated levels were found in $71 \%$, and in $35 \%$ levels were greater than $55 \mathrm{ng} / \mathrm{ml}$. In 32 of these patients levels ranged from 100 to over $500 \mathrm{ng} / \mathrm{ml}$. Of 53 patients with colonic carcinomata, the range did not differ significantly from the larger group, $68 \%$ having elevated levels, $34 \%$ being in excess of 55 $\mathrm{ng} / \mathrm{ml}$. The positivity rate in carcinoma of the pancreas, gallbladder, and bile ducts appears marginally higher $(85 \%)$ but numbers are small and the disease had reached an advanced state in most of these cases. The one patient with a pancreatic carcinoma who showed a normal CEA is of interest, in that at the time the specimen was taken an indurated

\begin{tabular}{|c|c|c|c|c|c|}
\hline & No. & $<12.5$ & $12 \cdot 5-55$ & $>55$ & $\begin{array}{l}\text { Percentage } \\
\text { Positive }\end{array}$ \\
\hline \multicolumn{6}{|l|}{ Malignant Tumours } \\
\hline Colon/rectum & 53 & 17 & 18 & 18 & 68 \\
\hline Stomach & 23 & 8 & 6 & 9 & 65 \\
\hline Pancreas & 8 & 1 & 5 & 2 & \\
\hline Ampulla of Vater & 1 & 1 & 0 & 0 & \\
\hline Gallbladder & 3 & 0 & 1 & 2 & \\
\hline Bile duct & 1 & $\mathbf{0}$ & 1 & 0 & \\
\hline Hepatoma & 1 & $\mathbf{0}$ & 1 & $\mathbf{0}$ & \\
\hline Oesophagus & 1 & 0 & 1 & 0 & \\
\hline Disseminated & 5 & 1 & 1 & 3 & \\
\hline $\begin{array}{l}\text { Total malignant } \\
\text { tumours }\end{array}$ & 96 & 28 & 34 & 34 & 71 \\
\hline $\begin{array}{l}\text { Benign Tumours } \\
\text { Colon }\end{array}$ & 3 & 3 & 0 & 0 & \\
\hline \multicolumn{6}{|l|}{ Inflammatory Diseases } \\
\hline Peptic ulcer & 21 & 18 & 3 & $\mathbf{0}$ & 14 \\
\hline Cholecystitis & 5 & 4 & 1 & $\mathbf{0}$ & \\
\hline Ulcerative colitis & 61 & 54 & 7 & $\mathbf{0}$ & 11 \\
\hline Crohn's disease & 58 & 50 & 8 & $\mathbf{0}$ & 14 \\
\hline Diverticular disease & 9 & 7 & 2 & $\mathbf{0}$ & \\
\hline Adult coeliac disease & 9 & 7 & 2 & $\mathbf{0}$ & \\
\hline Pancreatitis & 4 & 3 & 1 & 0 & \\
\hline Other & 5 & 4 & 1 & 0 & \\
\hline
\end{tabular}

Table I Serum CEA in gastrointestinal disease $(\mathrm{ng} / \mathrm{ml})$ head of the pancreas had been noted at an operation carried out for benign pathology elsewhere in the abdomen. He died eight months later, postmortem examination revealing generalized dissemination from a primary pancreatic carcinoma. Unfortunately the serum CEA was not estimated on this second occasion.

All three patients with colonic polyposis had normal CEA levels. Of these one had a solitary adenoma of the sigmoid colon containing carcinoma in situ, and another was a patient with familial polyposis also with premalignant changes.

Inflammatory diseases of the gastrointestinal tract are important in the differential diagnosis of endodermally derived malignancy. Of 172 patients with these disorders, $86 \%$ showed CEA levels within the normal range. A major proportion of elevated levels in this group occurred in patients with ulcerative colitis (11\% positive) and Crohn's disease $(14 \%$ positive). In patients with ulcerative colitis there was no correlation between the level of CEA and the length of history, degree of activity, or extent of colonic involvement. Three patients had premalignant changes (Morson and Pang, 1967) on rectal biopsy or on examination of the total colectomy specimen, and in one of these the CEA level was raised. The one patient in the group who developed an overt carcinoma had a normal CEA level whereas no tumours were found in six patients with raised levels. There was also no relationship between CEA concentration and the extent or activity of disease in the group with Crohn's disease. Nonetheless all patients with elevated levels did have disease of not less than seven years' standing (range 7-30 years: mean 18.1).

The results in the group of patients with liver disease are summarized in table II. Raised levels were evident in a high proportion, 21 of 32 being positive. There was no significant difference between the CEA levels in various categories or cirrhosis and it is of interest that two patients with acute viral hepatitis also

\begin{tabular}{lrrrll}
\hline & No. & $<12 \cdot 5$ & $12 \cdot 5-55$ & $>55$ & $\begin{array}{l}\text { Percentage } \\
\text { Positive }\end{array}$ \\
\hline Alcoholic cirrhosis & 5 & 1 & 4 & 0 & \\
$\begin{array}{l}\text { Cryptogenic cirrhosis } \\
\text { Primary biliary }\end{array}$ & 9 & 3 & 6 & 0 & \\
$\quad$ cirrhosis & 3 & 2 & 1 & 0 & \\
$\begin{array}{l}\text { Secondary biliary } \\
\text { cirrhosis }\end{array}$ & 1 & 0 & 1 & 0 & \\
$\begin{array}{l}\text { Chronic aggressive } \\
\quad \text { hepatitis }\end{array}$ & 7 & 3 & 4 & 0 & \\
$\begin{array}{l}\text { Alcoholic hepatitis } \\
\text { Viral hepatitis }\end{array}$ & 3 & 1 & 2 & 0 & \\
Other & 2 & 0 & 2 & 0 & \\
Total & 2 & 1 & 1 & 0 & \\
\hline
\end{tabular}

Table II Serum CEA in liver disease $(\mathrm{ng} / \mathrm{ml})$ 
showed raised values. In one patient with cryptogenic cirrhosis the level was within the normal range on a preliminary measurement but six months later after the development of progressive jaundice the CEA level had risen to $27 \mathrm{ng} / \mathrm{ml}$. He subsequently died and postmortem examination revealed the presence of a hepatocellular carcinoma.

\section{NON-GASTROINTESTINAL DISEASE}

The serum samples of 109 patients with malignant tumours arising in organs other than those of the gastrointestinal system have been examined, elevated levels being found in $42 \%$. The single patient whose level was in excess of $500 \mathrm{mg} / \mathrm{ml}$ suffered from IgG myeloma.

The majority of patients with benign tumours and all those with benign breast and prostatic disease had normal levels. In other disease groups levels were above the normal range in a significant proportion with rheumatoid arthritis, chronic respiratory disease, and other inflammatory disorders (table III).

\section{RELATIONSHIP TO TUMOUR STAGING}

The CEA levels have been analysed with respect to the tumour stage in colonic, gastric, and breast carcinomata, and the results are displayed in

\begin{tabular}{|c|c|c|c|c|c|}
\hline & No. & $<12 \cdot 5$ & $12 \cdot 5-55$ & $>55$ & $\begin{array}{l}\text { Percentage } \\
\text { Positive }\end{array}$ \\
\hline \multicolumn{6}{|l|}{ Malignant Tumours } \\
\hline Bronchus & 19 & 10 & 7 & 2 & 47 \\
\hline Breast & 42 & 27 & 10 & 5 & 36 \\
\hline Ovary & 4 & 4 & 0 & $\mathbf{0}$ & \\
\hline Cervix/uterus & 4 & 1 & 1 & 2 & \\
\hline Bladder & 3 & 1 & 2 & $\mathbf{0}$ & \\
\hline Prostate & 1 & $\mathbf{0}$ & 1 & $\mathbf{0}$ & \\
\hline Disseminated & 10 & 6 & 4 & 0 & \\
\hline Lymphoreticular & 4 & 3 & 1 & $\mathbf{0}$ & \\
\hline Leukaemia & 12 & 8 & 3 & 1 & \\
\hline Other & 10 & 3 & 7 & 0 & \\
\hline $\begin{array}{l}\text { Total malignant } \\
\text { tumours }\end{array}$ & 109 & 63 & 36 & 10 & 42 \\
\hline \multicolumn{6}{|l|}{ Benign Tumours } \\
\hline Bladder & 3 & 2 & 1 & $\mathbf{0}$ & \\
\hline Ovary & 3 & 2 & 1 & $\mathbf{0}$ & \\
\hline Thyroid & 3 & 3 & $\mathbf{0}$ & $\mathbf{0}$ & \\
\hline Salivary & 2 & 2 & $\mathbf{0}$ & 0 & \\
\hline \multicolumn{6}{|l|}{ Other Disorders } \\
\hline Benign breast disease & 11 & 11 & $\mathbf{0}$ & $\mathbf{0}$ & \\
\hline Benign prostatic disease & e 3 & 3 & $\mathbf{0}$ & $\mathbf{0}$ & \\
\hline Rheumatoid arthritis & 11 & 7 & 4 & $\mathbf{0}$ & \\
\hline \multicolumn{4}{|c|}{ Chronic respiratory } & & \\
\hline \multicolumn{6}{|l|}{ Other inflammatory } \\
\hline disorders & 21 & 14 & 7 & $\mathbf{0}$ & \\
\hline \multicolumn{6}{|l|}{ Postmyocardial } \\
\hline $\begin{array}{l}\text { infarction } \\
\text { Uraemia }\end{array}$ & $\begin{array}{r}12 \\
1\end{array}$ & $\begin{array}{r}11 \\
1\end{array}$ & $\begin{array}{l}1 \\
0\end{array}$ & $\begin{array}{l}0 \\
0\end{array}$ & \\
\hline
\end{tabular}

Table III Serum CEA in non-gastrointestinal disorders $(\mathrm{ng} / \mathrm{ml})$

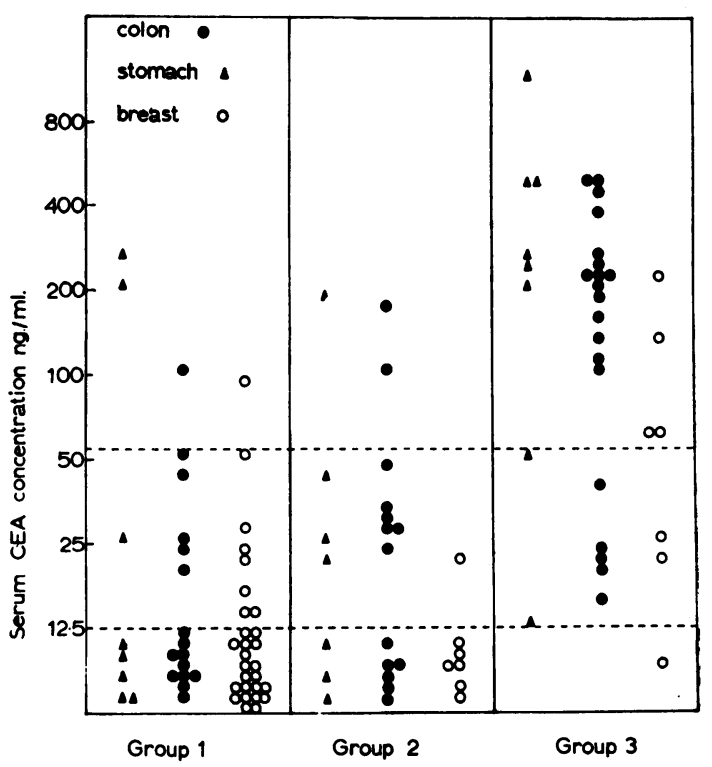

Fig 2 Comparison of serum CEA levels and tumour dissemination.

Group 1 Localized tumours without lymph node metastases.

Group 2 Tumours with local lymph node metastases.

Group 3 Spread to liver, lung, or bone.

figure 2. A minority of patients without lymph node involvement (group 1) have raised levels. Where spread has occurred to the local lymph nodes, but resection is still practicable (group 2), the proportion rises, and where generalized dissemination has occurred $92 \%$ are positive (group 3 ). In many of these the level was greater than $100 \mathrm{ng} / \mathrm{ml}$.

THE RESPONSE TO THERAPY AND THE DETECTION OF RECURRENT TUMOUR

We have studied 19 patients at intervals up to 14 days after the removal of a colonic carcinoma, and results from 11 patients with localized tumours are shown in figure 3 . In three, raised levels fell to normal by the end of the first week and although two others showed elevated concentrations for seven days, these became normal within two weeks. One patient with an initially normal level developed a raised level at the end of the first week, but she unfortunately died from a pulmonary embolism two days later. A second with an initial value of $100 \mathrm{ng} / \mathrm{ml}$ showed a. fall in CEA level at the end of the first week, but seven days later it had risen again to $70 \mathrm{ng} / \mathrm{ml}$. This rise was associated with the development of intraabdominal sepsis and three months after the opera- 


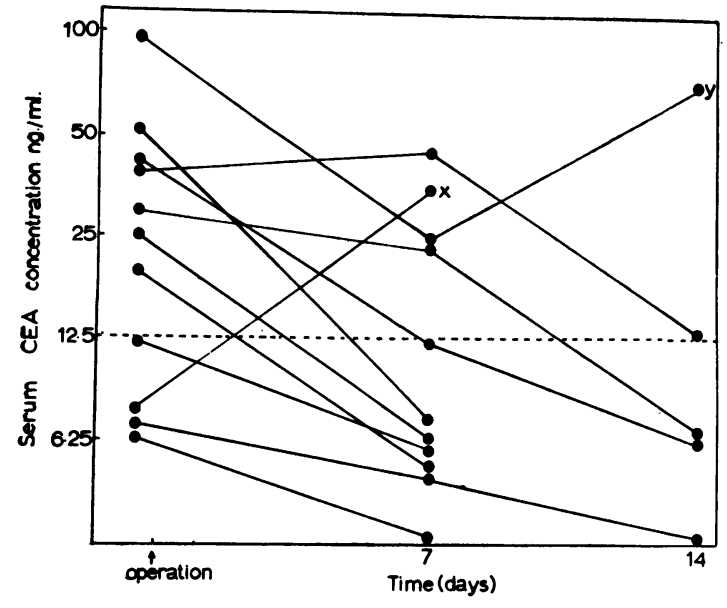

Fig 3 The effect of surgical excision of localized tumours on the serum CEA concentration.

$X$-patient died from a pulmonary embolism. $Y$-patient developed intraabdominal sepsis.

tion there was no clinical evidence of tumour recurrence although a further CEA estimation has not been made.

Estimations of CEA have been made on 33 patients attending a follow-up clinic between three months and six years after resection of a colonic or rectal carcinoma. In 21 of these, levels were normal and one patient had evidence of tumour recurrence at the site of a previous anastomosis. Of 12 patients with elevated levels, 10 had evidence of tumour recurrence or have developed signs of recurrence within three months of the CEA estimation.

\section{Discussion}

The double antibody radioimmunoassay for the estimation of CEA in peripheral blood samples has been shown by Laurence et al (1972) to produce results comparable in a clinical context with those using the Farr technique (Moore et al, 1971; Joint Canadian and American Study, 1972) or the Z-gel assay (Lo Gerfo et al, 1971). It does not involve perchloric acid extraction, is quicker to perform, and requires less serum $(0.4 \mathrm{ml})$. It also appears to be more readily adaptable to automation procedures, and thus it is imperative to define its value in the assessment of practical clinical problems.

The higher range of normal values obtained by this method is possibly related to the use of unextracted serum, and it is possible that other serum proteins which would be removed by perchlorate extraction might interfere with the assay thus producing a positive result. Comparison of serum concentrations of a range of eight such proteins with CEA has been completed and this possibility appears unlikely (Paine, King, Leonard, Booth, and Dykes, 1973). Carcinoembryonic antigen has been demonstrated in normal human plasma (Chu et al, 1972) but it remains to be established whether high control values are due to CEA or to some other substance interfering with the assay. The clinical value of the assay, however, does not depend on the upper limit set to the normal range but rather on the effective separation of normal from abnormal. Further studies on this normal range are in progress and for this report we have chosen to use the range of 0 to $12.5 \mathrm{ng} / \mathrm{ml}$ suggested by Laurence et al (1972), which appears compatible with our own findings. By this standard, the present results are compatible with those obtained either by the double antibody or other assays, approximately $70 \%$ positivity being obtained in carcinoma of the colon/rectum, stomach, and pancreas, and $40 \%$ from those with other malignant tumours. A much smaller yield of positive results might be acceptable provided they include early lesions, and it is important to find that for tumours of colon, stomach, and breast which have not yet apparently involved lymph nodes, positive results were found in 37,33 , and $21 \%$ respectively. It further appears that in patients with carcinoma of the colon values greater than $100 \mathrm{ng} / \mathrm{ml}$ indicate widespread metastases, a finding which might also be of clinical value.

As for most laboratory tests, potential value depends both on the unambiguous separation of the pathological from the normal, and on a similarly clear separation from other disease groups, which frequently give diagnostic difficulty. By this latter criterion, CEA assay has, after the first exciting report from Thomson et al (1969), been disappointing. The diagnostic usefulness now depends on proportional rates of positivity, although recently Laurence et al (1972) have emphasized the importance of concentration. We were fortunate in having large groups of patients suffering from inflammatory bowel disease, and within this other 'control' group no patient had a CEA concentration of greater than $55 \mathrm{ng} / \mathrm{ml}$. This level also applies to non-gastrointestinal non-malignant disease, and therefore appears to be the best additional level to set to give information of maximal clinical value. Below this level, CEA concentration could still be of diagnostic value, as all patients in the non-malignant disease groups had clear diagnostic labels and abnormal values would not necessarily lead to confusion. The difficulties in assessing a new clinical test in groups of fully diagnosed patients are, however, well known, and the more important question of its value in the undiagnosed patient is one which we are now 
studying. Claims have already been made that abnormal values in patients with apparently nonmalignant diseases frequently turn out to indicate the presence of cancer (Lo Gerfo et al, 1971), but this question urgently requires further study.

One further limitation to the usefulness of this test is the relationship of concentration to the spread of the disease, and it is disappointing that early lesions are usually associated with normal values. Nevertheless, by combining data from this and the other published study utilizing the double antibody test (Laurence et al, 1972), it appears that approximately one fifth of patients with early and localized lesions have CEA concentrations greater than 40 $\mathrm{ng} / \mathrm{ml}$ and in at least two-fifths of patients it is greater than $12.5 \mathrm{ng} / \mathrm{ml}$. Whether this information is of diagnostic usefulness will only be answered by the prospective study of undiagnosed patients which is now in progress.

Another and perhaps more promising area in which CEA might be of value is in the progressive study of patients with pre-malignant or treated malignant conditions. The small amount of data we have of positive values in longstanding ulcerative colitics is not encouraging in terms of the predictive value in the development of cancer, but much more information is necessary before an authoritative view is possible. In cancer follow up, however, correlation with recurrence appears better, as previously reported (Laurence et al, 1972). Following initial surgical resection it has been shown that the fall in concentration is related to the completeness of removal (Thomson et al, 1969; Laurence et al, 1972; Dhar, Moore, Zamcheck, and Kupchik, 1972), a finding supperted by our own data. Further, the presence of elevated concentrations in 10 of 12 patients with recurrence of colonic cancer underlines the possible applications in follow up. Surgical opinion in this condition often favours second-look surgery (Gilbertsen and Wangensteen, 1962), the timing of which could readily be influenced by this test. Whether such increases occur early enough to be of real value is a problem of great importance and is also under active study.

This work is being carried out through the support of the Medical Research Council. We are indebted to clinical colleagues for access to suitable patients and to Miss Hilary van Baars for technical assistance.

\section{References}

Bagshawe, K. D. (1969). Choriocarcinoma: The Clinical Biology of the Trophoblast and its Tumours, pp. 153-155. Arnold, London.

Chu, T. M., Reynoso, G., and Hansen, H. J. (1972). Demonstration of carcinoembryonic antigen in normal human plasma. Nature (Lond.), 238, 152-153.

Coligan, J. E., Lautenschleger, J. T., Egan, M. L., and Todd, C. W. (1972). Isolation and characterization of carcinoembryonic antigen. Immunochemistry, 9, 377-386.

Dhar, P., Moore, T., Zamcheck, N., and Kupchik, H. Z. (1972). Carcinoembryonic antigen in colonic cancer. J. Amer. med. Ass., 221, 31-35

Dukes, C. E. (1940). Cancer of the rectum: an analysis of 1000 cases. J. Path. Bact., 50, 527-539.

Egan, M. L., Lautenschleger, J. T., Coligan, J. E., and Todd, C. W. (1972). Radioimmunoassay of carcinoembryonic antigen. Immunochemistry, 9, 289-299.

Gilbertsen, V. A., and Wangensteen, O. H. (1962). A summary of thirteen years' experience with the second look program. Surg. Gynec. Obstet., 114, 438-442.

Gold, P., and Freedman, S. O. (1965a). Demonstration of tumour specific antigens in human colonic carcinomata by immunological tolerance and absorption techniques. J. exp. Med., 121, 439-462.

Gold, P., and Freedman, S. O. (1965b). Specific carcinoembryonic antigens of the human digestive system. J. exp. Med., 122 , 467-481.

Joint National Cancer Institute of Canada/American Cancer Society Investigation (1972). A collaborative study of a test for carcinoembryonic antigen (CEA) in the sera of patients with carcinoma of the colon and rectum. Canad. med. Ass. J., 107, 25-33.

Kennedy, B. J. (1970). TNM Classification for Stomach Cancer. Cancer (Philad.), 26, 971-983.

Laurence, D. J. R., Stevens, U., Bettelheim, R., Darcy, D., Leese, C., Turberville, C., Alexander, P., Johns, E. W., and Neville, A. M. (1972). Role of plasma carcinoembryonic antigen in diagnosis of gastrointestinal, mammary, and bronchial carcinoma. Brit. med. J., 3, 605-609.

Lo Gerfo, P., Krupey, J., and Hansen, H. J. (1971). Demonstration of an antigen common to several varieties of neoplasia. New Engl. J. Med., 285, 138-141.

Martin, F., and Martin, M. S. (1970). Demonstration of antigens related to colonic cancer in the human digestive system. Int. J. Cancer, 6, 352-360.

Moore, T. L., Kupchik, H. Z., Marcon, N., and Zamcheck, N. (1971). Carcinoembryonic antigen assay in cancer of the colon and pancreas and other digestive tract disorders. Amer. J. dig. Dis., $16,1-7$.

Morson, B. C., and Pang, L. S. C. (1967). Rectal biopsy as an aid to cancer control in ulcerative colitis. Gut, 8, 423-434.

Old, L. J., Boyse, E. A., Clarke, D. A., and Carswell, E. A. (1962). Antigenic properties of chemically induced tumors. Ann. N.Y. Acad. Sci., 101, 80-106.

Paine, M., King, J. P. G., Leonard, J., Booth, S. N., and Dykes, P. W. (1973). An examination of the possible inter-relationships between serum concentrations of carcinoembryonic antigen and other glycoproteins. (Unpublished.)

Thomson, D. M. P., Krupey, J., Freedman, S. O., and Gold, P. (1969). The radioimmunoassay of circulating carcinoembryonic antigen of the human digestive system. Proc. nat. Acad. Sci. (Wash.), 64, 161-167. 